\title{
Appraisal of Hybrid Fiber Reinforced Engineered Cementitious Composite
}

\author{
Maninder Singh, Babita Saini, H. D. Chalak \\ Civil Engineering Department, National Institute of Technology Kurukshetra \\ Haryana, India \\ maninder_6160049@nitkkr.ac.in; bsaini@nitkkr.ac.in; chalakhd@nitkkr.ac.in
}

\begin{abstract}
Mortar based engineered cementitious composite (ECC) demonstrate strain hardening behaviour with multiple micro-cracks under tension. The distinctive behaviour of ECC, makes it ductile as compared to brittle nature of conventional concrete. Ductile nature of ECC, makes it applicable in seismic resistant, repairing and retrofitting areas and blast resistant structural elements. In the present investigation, two types of polymer fibers (i.e. polyester (PET) fiber and polyvinyl alcohol (PVA) fiber) have been used in hybridization with different percentages $(2+0),(2+0.5),(1.75+0.5),(1.5+0.5)$ for making ECC. Also fly ash, 55\% of the total cementitious material, has been used for making sustainable concrete. The compressive, flexural and tensile tests were performed to evaluate the mechanical behaviour of hybrid fiber reinforced cementitious matrix. The test results revealed that PET fiber and PVA fiber in combination enhanced the strength properties of ECC by bridging effect of hybrid fibers.
\end{abstract}

Keywords: Polyester fiber, Polyvinyl alcohol, Fly ash, Quartz powder, Amalgam.

\section{Introduction}

In the last two decades the construction with high strength concrete has increased. The use of high strength concrete (HSC) increase the brittleness in concrete, with the increase in brittle numbers. Due to brittle nature of ordinary concrete, use of HSC is very risky for the construction in earthquake prone zones. Advancement in the production of fiber reinforcing material increased in last few decades and the research works to find the effectiveness of materials are ongoing from 60's to till date $[1,2]$. Modern fiberocrete arrest the crack width, improved the mechanical parameters and also change the behaviour of concrete as depicted in Figure 1. Li Victor C. in early 1990's introduced a distinctive class of strain hardening fiber reinforced cementitious composite (SHFRCC) i.e. Engineered cementitious composite (ECC). The pseudo strain hardening behaviour of ECC makes it highly ductile. ECC is cement based strain hardening ductile cementitious composite [3-6]. Ingredients of ECC are similar to fiber reinforced concrete. Coarse aggregates are excluded as they affect the distinct ductile nature of cementitious composite. The regular concrete and fiber reinforced concrete (FRC) undergoes brittle and strain softening failure, whereas ECC exhibits strain hardening behaviour with multiple micro cracks [7, 8]. ECC is a wacky branch of FRC, which consists of different types of short length polymeric fibers. Fiber inclusion in cementitious matrix enhanced the tensile strain capacity and ductility through fiber bridging process. Fiber bridging provides resistance to crack width and transfer stresses across the cracks $[9,10]$. The diversity of fibers such as polyethylene, steel fibers, polyvinyl alcohol, polypropylene, etc. have been used in ECC. In recent hybrid mixtures in combination with varied fiber shapes and dimensions have been arising. Numerous researchers reported that amalgam of two or more fibers with different properties (types, lengths, diameters, elastic modulus, elongation and tensile strength) can produce composites with better strength and strain parameters than mono fiber containing composites [10-16].

Extremely polyvinyl alcohol (PVA) fiber have been used to reinforce engineered cementitious matrix [17-19]. Hydrophilic nature of PVA fiber in cementitious matrix develop strong chemical bond. Due to strong chemical bonding PVA fibers rupture than pullout, which limits the pseudo strain hardening behaviour of cementitious matrix [20-22]. Some of the researchers used oil coated PVA fiber to reinforce cement matrix, which demonstrate good agreement of fiber matrix interactions [23]. As the PVA fiber cost is very high so, it is not convenient to use these fibers in extenso for making ECC. Many efforts have been made to make cost effective ECC with hybridization of fibers. High and low modulus fibers in combination enhanced the mechanical properties of ECC $[24,25]$. The past studies showed that the utilization of fly ash 
(FA) in high volume improve the tensile strain capacity, interaction between fiber-matrix and chemical bond interface; whereas decreased the strength properties with PVA fiber [26, 27].

Polyester (PET) fiber is another alternative class of polymeric fiber, as it costs $1 / 5$ times cheaper than PVA fiber. The author [28] reported that intrusion of polyester fiber in ECC as a bed joint gave better performance than cement mortar. The literature showed that very few studies have been carried out with polyester and PVA fiber hybridization in ECC. The object of this study is to determine strength properties (i.e. compressive, tensile and flexural) with hybridization of fibers at different percentages.

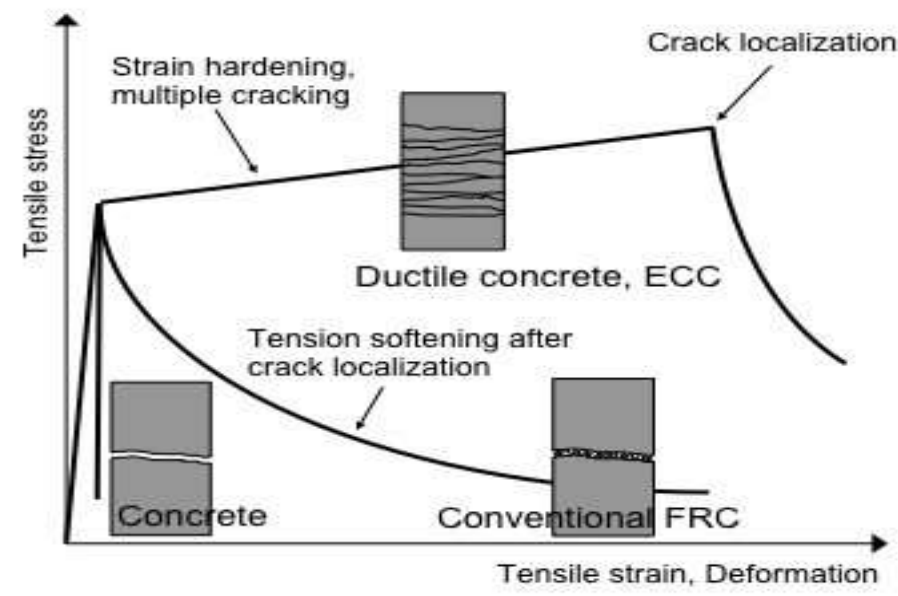

Fig. 1: Response of concrete, FRC and ECC under tensile loading [29].

\section{Experimental Details}

\subsection{Materials}

The constituents of ordinary ECC are Portland cement (PC), micro silica sand, FA, water, superplasticizer (SP) and polymer fibers (to reinforce cementitious matrix). In the present study, Portland cement (PC) as binder, quartz powder $(\mathrm{QP})$ with size $(175 \mu \mathrm{m})$, class F-fly ash as supplementary cementitious material and Master Glenium Sky 8233 as high range water reducer were used to prepare the mix. Two types of polymer fibers, i.e. polyvinyl alcohol (PVA) and polyester (PET) fiber of triangular shape to reinforce the ECC were used in this research work. The characteristics of $\mathrm{PC}$ and polymer fibers have been given in table 1 and 2.

Table 1: Physical and mechanical characteristics of PC.

\begin{tabular}{|c|c|c|c|c|c|c|c|c|c|}
\hline \multirow[t]{2}{*}{ Property } & \multirow{2}{*}{$\begin{array}{l}\text { Specific } \\
\text { gravity } \\
\left(\mathrm{g} / \mathrm{cm}^{3}\right)\end{array}$} & \multirow{2}{*}{$\begin{array}{l}\text { Initial } \\
\text { setting } \\
\text { time } \\
\text { (IST), } \\
\text { min }\end{array}$} & \multirow{2}{*}{$\begin{array}{l}\text { Final } \\
\text { setting } \\
\text { time } \\
(\mathrm{FST}) \text {, } \\
\text { min }\end{array}$} & \multirow[t]{2}{*}{$\begin{array}{l}\text { Consistency } \\
(\%)\end{array}$} & \multirow[t]{2}{*}{$\begin{array}{l}\text { Fineness } \\
(\%)\end{array}$} & \multirow[t]{2}{*}{$\begin{array}{l}\text { Soundness } \\
(\mathrm{mm})\end{array}$} & \multicolumn{3}{|c|}{$\begin{array}{l}\text { Compressive strength } \\
\text { (MPa) }\end{array}$} \\
\hline & & & & & & & $3 d$ & $7 d$ & $28 \mathrm{~d}$ \\
\hline Value & 3.14 & 109 & 310 & 28.5 & 4 & 5 & 26.40 & 35.75 & 44.36 \\
\hline
\end{tabular}


Table 2: Physical characteristics of polymer fibers.

\begin{tabular}{|c|c|c|c|c|c|c|c|}
\hline $\begin{array}{c}\text { Type of } \\
\text { fiber }\end{array}$ & $\begin{array}{c}\text { Diameter } \\
(\mathrm{d}), \mathrm{mm}\end{array}$ & $\begin{array}{c}\text { Length } \\
(\mathrm{L}), \\
\mathrm{mm}\end{array}$ & $\begin{array}{c}\text { Aspect ratio } \\
(\mathrm{L} / \mathrm{D})\end{array}$ & $\begin{array}{c}\text { Tensile } \\
\text { strength } \\
(\mathrm{MPa})\end{array}$ & $\begin{array}{c}\text { Elongation } \\
(\%)\end{array}$ & $\begin{array}{c}\text { Young's } \\
\text { modulus } \\
(\mathrm{GPa})\end{array}$ & $\begin{array}{c}\text { Density } \\
\left(\mathrm{g} / \mathrm{cm}^{3}\right)\end{array}$ \\
\hline $\begin{array}{c}\text { Polyester } \\
\text { fiber }\end{array}$ & $\begin{array}{c}0.025- \\
0.035\end{array}$ & 12 & 400 & 480 & 30 & -- & 1.31 \\
\hline $\begin{array}{c}\text { PVA } \\
\text { fiber }\end{array}$ & 0.04 & 12 & 300 & 1600 & 7 & 42.8 & 1.3 \\
\hline
\end{tabular}

\subsection{Mix proportion}

To interpret the effect of fiber hybridization on strength parameters of ECC, different four mix proportions were designed and designated as given in table 3.

Table 3: Different mix proportion of hybrid cement- matrix (\%).

\begin{tabular}{|c|c|c|c|c|c|c|c|}
\hline & \multicolumn{7}{|c|}{ Ingredients } \\
\cline { 2 - 8 } Mix ID & Cement & Fly ash & QP & w/b & $\begin{array}{l}\text { Polyester } \\
\text { fiber (\%) }\end{array}$ & $\begin{array}{l}\text { PVA fiber } \\
(\%)\end{array}$ & SP (\%) \\
\hline 2PE0PV & 1 & 1.2 & 0.8 & 0.27 & 2 & 0 & 0.75 \\
\hline 2PE0.5PV & 1 & 1.2 & 0.8 & 0.27 & 2 & 0.5 & 0.75 \\
\hline $\begin{array}{c}1.75 P E 0.5 P \\
\text { V }\end{array}$ & 1 & 1.2 & 0.8 & & 1.75 & 0.5 & 0.75 \\
\hline $1.5 P E 0.5 P V$ & 1 & 1.2 & 0.8 & 0.27 & 1.5 & 0.5 & 0.75 \\
\hline
\end{tabular}

\subsection{Mixing and specimen preparations}

The cement matrix was prepared using power driven mortar mixer. Mixing process comprises following steps: Step 1: All dry solid ingredients i.e. cement, quartz powder and FA were mixed for about 2-3 minutes in the mortar mixer. Step 2: Water was added in the mixed constituents along with SP and the mixer was rotated for the next 5 minutes. Step 3: Finally, fibers were added by spreading and mixing process continued in mixer until homogeneity achieved. The whole mixing process took about 10-12 minutes.

After obtaining homogeneous mix, cubes $(70.6 \mathrm{~mm} \times 70.6 \mathrm{~mm} \times 70.6 \mathrm{~mm})$, tensile coupons $(310 \mathrm{~mm} \times 100 \mathrm{~mm} \times 20$ $\mathrm{mm})$, and rectangular prisms $(500 \mathrm{~mm} \times 100 \mathrm{~mm} \times 100 \mathrm{~mm})$ were casted. A membrane of lubricating agent was applied on the interior sides of the moulds before pouring the cementitious mix into the moulds. The samples were demoulded after 24 hours and immersed in the water tank for required curing.

\section{Experimental methods and Testing procedures}

\subsection{Compression test}

For each mix three cubes were taken for compressive strength (CS) and tested in the CTM (Compression testing machine) with $1000 \mathrm{kN}$ capacity after required age as per IS 516:1959 [30]. The applying rate of loading was kept 3 $\mathrm{kN} / \mathrm{second}$ until failure occurs. 


\subsection{Tensile strength}

For each mix proportion three coupons $(310 \mathrm{~mm} \times 100 \mathrm{~mm} \times 20 \mathrm{~mm})$ were tested in hydraulic Universal Testing Machine (UTM) and loading rate was $0.5 \mathrm{~mm} /$ minute. The gauge length was maintained $80 \mathrm{~mm}$ with $40 \mathrm{~mm}$ width in specimen.

\subsection{Flexural test}

Four point bending tests was performed to evaluate the flexural stress, three prism specimens for each mix proportion were tested [31, 32].

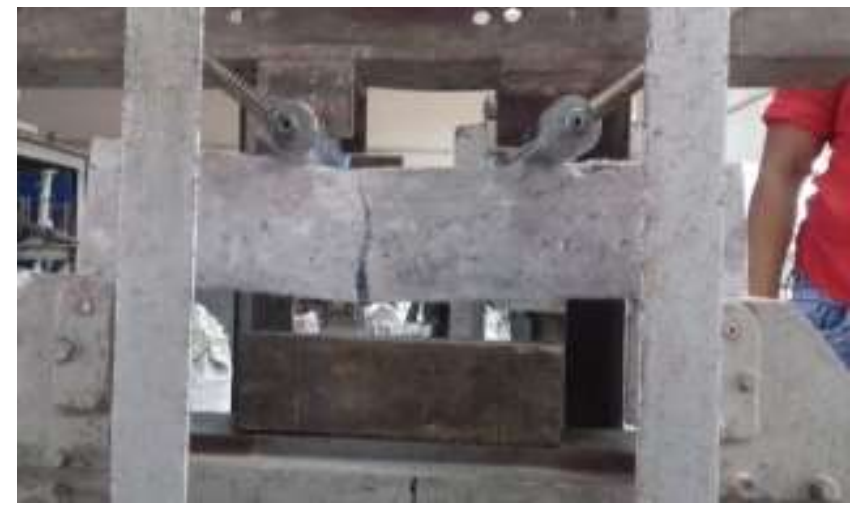

Fig. 2: Failure pattern of rectangular prism under bending test.

\section{Experimental results and discussion}

The strength properties of different mix proportions have been illustrated in the Figures 3-5. The performance of different mix proportions was analysed on the basis of recorded strength parameters (i.e. compressive, tensile and flexural).

\subsection{Compressive strength}

It has been noticed from figure 3 that the strength in compression of 2PE0PV at 28 days was $48.56 \mathrm{MPa}$. For hybridization of fibres i.e. 1.5PE0.5PV, 1.75PE0.5PV and 2PE0.5PV, the CS varied from 49.88 MPa to 51.28 MPa. The compressive strength of mix proportions i.e. 1.5PE0.5PV, 1.75PE0.5PV and $2 \mathrm{PE} 0.5 \mathrm{PV}$ enhanced by $6 \%, 5 \%$ and $3 \%$ respectively in comparison to mix $2 \mathrm{PEOPV}$ at 28 days. 


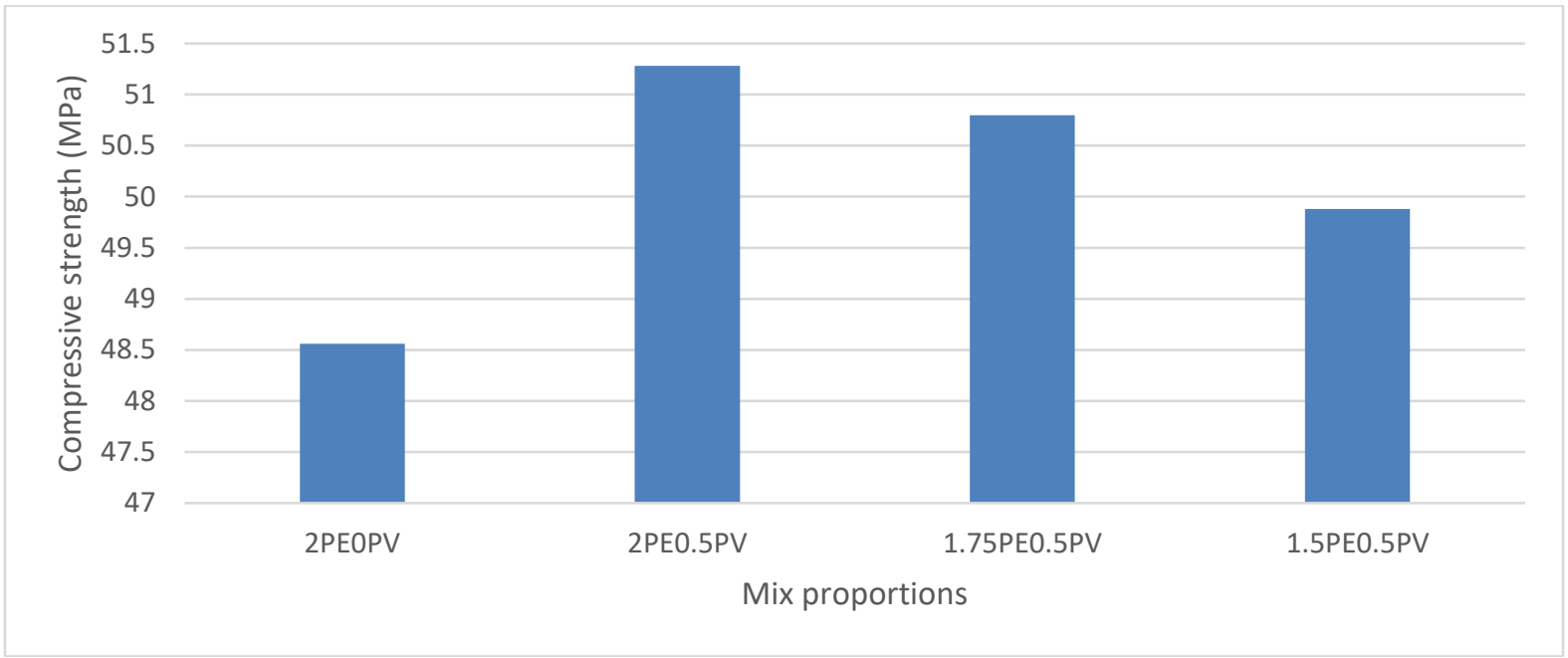

Fig. 3: Compressive strength of various mix proportions after 28 days curing.

\subsection{Tensile strength}

It has been observed from figure 4 that the tensile strength of 2PE0PV at 28 days was $2.64 \mathrm{MPa}$. For hybridization of of fibres i.e. 1.5PE0.5PV, 1.75PE0.5PV and 2PE0.5PV, the tensile strength varied from $3.15 \mathrm{MPa}$ to $3.92 \mathrm{MPa}$. The tensile strength of mix proportions i.e. 1.5PE0.5PV, 1.75PE0.5PV and 2PE0.5PV enhanced by $19 \%, 32 \%$ and $48 \%$ respectively in comparison to mix $2 \mathrm{PE} 0 \mathrm{PV}$ at 28 days.

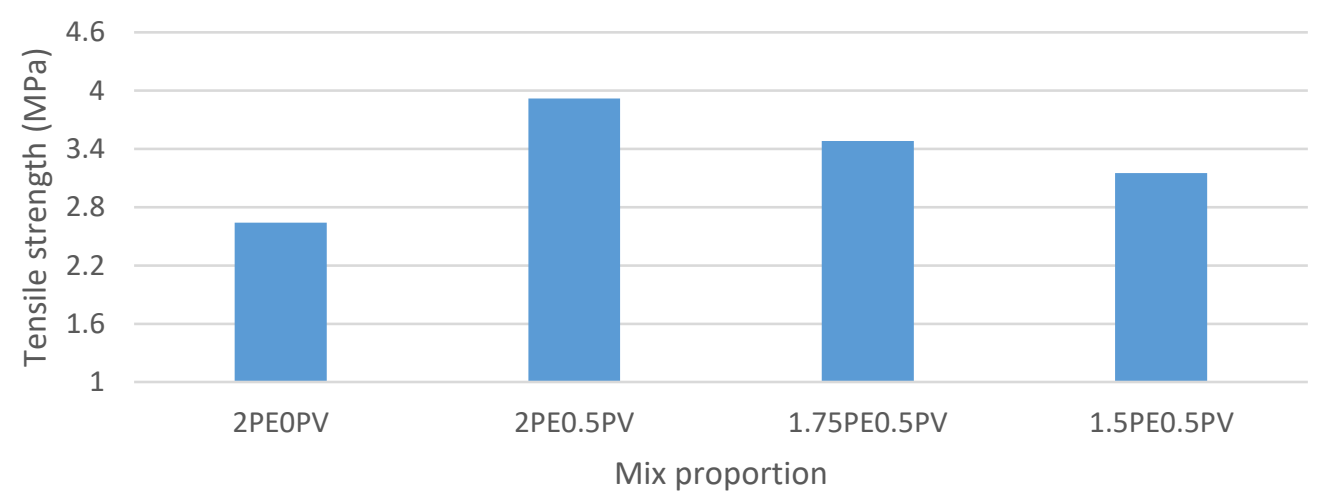

Fig. 4: Tensile strength of various mix proportions after 28 days curing.

\subsection{Flexural strength}

It has been observed from figure 5 that the flexural strength of $2 \mathrm{PEOPV}$ at 28 days was $7.46 \mathrm{MPa}$. For hybridization of fibres i.e. 1.5PE0.5PV, 1.75PE0.5PV and 2PE0.5PV, the flexural strength varied from $7.88 \mathrm{MPa}$ to $8.78 \mathrm{MPa}$. The flexural strength of mix proportions i.e. 1.5PE0.5PV, 1.75PE0.5PV and $2 \mathrm{PE} 0.5 \mathrm{PV}$ enhanced by $6 \%, 10 \%$ and $18 \%$ respectively in comparison to mix $2 \mathrm{PE} 0 \mathrm{PV}$ at 28 days. 


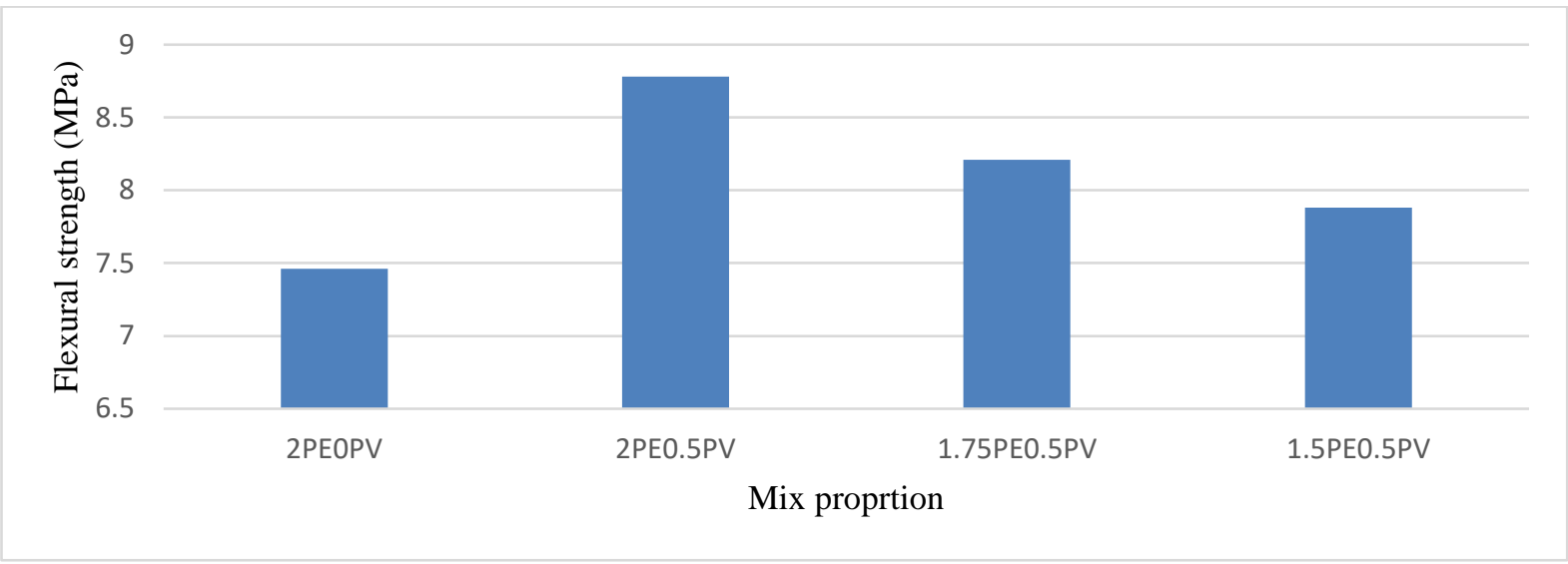

Fig. 5: Flexural strength of various mix proportions after 28 days curing.

\section{Conclusions}

In the current study, the impact of hybridization of fibers on the strength parameters of ECC was evaluated. The major key findings from the above study have been mentioned below:

- The strength properties (i.e. compressive, tensile and flexural) were found to be increased with the use of PET and PVA fiber in hybridization.

- The mechanical properties were found optimum with the use of $2 \%$ PET and $0.5 \%$ PVA fibers in hybridization.

- The strength in tension and bending of 2PE0.5PV mix were found 48\% and 18\% higher than 2PE0PV mix.

- Enhancement in strength parameters may be attributed to fiber bridging, which increased the load carrying capacity with multiple micro cracks behaviour and transferred the stresses across the cracks.

- Hybridization of fibers improved the mechanical properties in comparison to polyester fiber alone. PET was found the best alternative option to use in ECC with amalgam or alone as per properties required.

- The use of PET and PVA in amalgam decreased the total cost of ECC, and also encourage the use of ECC on large scale.

\section{Acknowledgements}

The authors feel obliged to Kuraray India Limited and Reliance India Limited for providing fibers for the research study.

\section{References}

[1] J. P. Romualdi, J. A. Mandel, "Tensile strength concrete affected by uniformly distributed closely spaced short length of wire reinforcement," Proc. ACI J., vol. 61, no. 6 pp. 657-671, 1994.

[2] N. P. Romualdi, G. B. Batson, "Mechanics of crack arrest in concrete," Proc. ASCE Eng. Mech. J., vol. 89, pp. 147-168, 1963.

[3] V. C. Li, "Engineered Cementitious Composites - Tailored Composites through Micromechanical Modeling," in Fiber Reinforced Concrete: Present and the Future, N. Banthia, A. Bentur, A. and A. Mufti, Eds. Montreal: Canadian Society for Civil Engineering, 1998, pp. 64-97.

[4] G. Xinchun, L. Yazhao, L. Tianan, Z. Chenchen, L. Hui, O. Jinping, "An economical ultra-high ductile engineered cementitious composite with large amount of coarse river sand," Construction and Building Materials, vol. 201, pp. 461-472, 2019.

[5] S. Pourfalah, "Behaviour of engineered cementitious composites and hybrid engineered cementitious composites at high temperatures," Construction and Building Materials, vol. 158, pp. 921-937, 2018. 
[6] A. Farhad, W. Lining, "Fabrication and characterization of an engineered cementitious composite with enhanced fire resistance performance," Journal of Cleaner Production, vol. 221, pp. 202-214, 2019.

[7] V. C. Li and T. Kanda, "Engineered cementitious composites for structural applications," J. Materials in civil engineering, vol. 10, pp. 66-69, 1998.

[8] M. Singh, B. Saini, and H. D. Chalak, "Properties of engineered cementitious composites: A Review," in Proceedings of the ICSWMD 2018, LNCE 21, pp. 1-11, 2019.

[9] Y. Chen, and P. Qiao, "Crack growth width resistance of hybrid fiber reinforced cement matrix composites," Journal of aerospace engineering, vol. 24, pp. 154-161, 2011.

[10] J.S. Lawler, D. Zampini, and S.P. Shah, "Microfiber and macro fiber hybrid fiber-reinforced concrete," J. Mater Civ Engg., vol. 17, pp. 595-604, 2005.

[11] S. F. U. Ahmed, H. Mihashi, "Strain hardening behavior of lightweight hybrid polyvinyl alcohol (PVA) fiber reinforced cement composites," Mater. Struct., vol. 44, pp. 1179-1191, 2011.

[12] D. L. Nguyen, D. J. Kim, G. S. Ryu, K. T. Koh, "Size effect on flexural behavior of ultra-high-performance hybrid fiber-reinforced concrete," Compos. Part B-Eng., vol. 45, pp. 1104-1116, 2013.

[13] N. Banthia, S. M. Soleimani, "Flexural response of hybrid fiber reinforced cementitious composites," ACI Mater. J., vol. 102, no. 6, pp. 382-389, 2005.

[14] E. R. Silva, J. F. J. Coelho, J. C. Bordado, "Strength improvement of mortar composites reinforced with newly hybridblended fibres: influence of fibres geometry and morphology," Constr. Build. Mater., vol. 40, pp. 473-480, 2013.

[15] N. Banthia, N. Nandakumar, "Crack growth resistance of hybrid fiber reinforced cement composites," Cement Concr. Compos., vol. 25, pp. 3-9, 2003.

[16] J. Zhang, M. Maalej, S.T. Quek, "Performance of hybrid-fiber ECC blast/shelter panels subjected to drop weight impact," J. Mater. Civ. Eng., vol. 19, no. 10, pp. 855- 863, 2007.

[17] X. Huang, R. Ranade, Q. Zhang, W. Ni, and VC. Li, "Mechanical and thermal properties of green lightweight engineered cementitious composites," Construction and Building Materials, vol. 48, pp. 954-960, 2013.

[18] J. Zhou, J. Pan, and C.K.Y. Leung, "Mechanical behaviour of fiber- reinforced engineered cementitious composites in uniaxial compression," Journal of Materials in Civil Engineering., vol. 27, 2014.

[19] T. K. Erdem, "Specimen size effect on the residual properties of engineered cementitious composites subjected to high temperatures," Cement and Concrete Composites, vol. 45, pp. 1-8, 2014.

[20] C. Redon, V. C. Li, C. Wu, H. Hoshiro, T. Saito, and A. Ogawa, "Measuring and modifying interface properties of PVA fibers in ECC matrix," J. Mater. Civ. Eng., vol. 13, pp. 399-406, 2001.

[21] V.C. Li, D. K. Mishra, and H. W. Wu, "Matrix design for pseudo strain-hardening fiber reinforced cementitious composites," Materials and Structures, vol. 28, pp. 586-595, 1995.

[22] T. Kanda, and V. C. Li, "Interface property and apparent strength of high-strength hydrophilic fiber in cement matrix," Journal of Material in Civil Engineerin., vol. 10, pp. 5-13, 1998.

[23] Z. Pan, C. Wu, J. Liu, W. Wang, and J. Liu, "Study on mechanical properties of cost-effective polyvinyl alcohol engineered cementitious composites (PVA-ECC)," Construction and Building Materials, vol. 78, pp. 397-404, 2015.

[24] A. Kawamata, H. Mihashi, and H. Fukuyama, "Properties of hybrid fiber reinforced cement-based composites," $J A d v$ Concr Technol., vol. 1, pp. 283-290, 2003.

[25] M. Maalej, S.T. Quek, and J. Zhang, "Behavior of hybrid-fiber engineered cementitious composites subjected to dynamic tensile loading and projectile impact," Journal of materials in civil engineering, vol. 17, pp. 143-152, 2005.

[26] E. H. Yang, Y. Yang, and V. C. Li, "Use of high volumes of fly ash to improve ECC mechanical properties and material greenness," ACI Materials Journal, vol. 104, pp. 303-311, 2007.

[27] Z. Zhang, S. Qian, and H. Ma, "Investigating mechanical properties and self-healing behavior of micro-cracked ECC with different volume of fly ash," Construction and Building Materials, vol. 52, pp. 17-23, 2014.

[28] S. B. Singh, P. Munjal, "Strengthening of masonry beams with ECC as bed joint," Journal of Engineering Science and technology, vol. 8, pp. 29-39, 2016. 
[29] M. D. Lepech, V. Popovici, G. Fischer, V. C. Li, R. Du, "Improving Concrete for Enhanced Pipeline Protection," Pipeline and Gas journal, vol. 237, no. 3, 2010.

[30] IS 516-1959, "Methods of tests for strength of concrete (18th Ed.)," New Delhi: Bureau of Indian Standards, 2006.

[31] M. R. A. Rama, K. Ramanjaneyulu (Eds.), "Recent Advances in Structural Engineering, Volume 1," Springer Nature Inc. America, 2016.

[32] H. Singh, P. Garg, I. Kaur (Eds.), "Proceedings of the 1st International conference on sustainable waste management through Design," Springer Nature Inc. America, 2019. 